\title{
TRANSFORMING EARTH INTO HOUSES: A METHODOLOGY FOR DOCUMENTING CONSTRUCTION PROCESSES AS AN APPRENTICE IN THE IRANIAN DESERT, SOUTH KHORASAN
}

\author{
E. P. Ferrari ${ }^{1, *}$ \\ ${ }^{1}$ Oxford Brookes Univeristy, PhD Student, School of Architecture, Headington Campus \\ Oxford, OX3 0BP - edoardo.ferrari-2019@brookes.ac.uk
}

Commission II - WG II/8

KEY WORDS: Traditional Construction Processes, Apprenticeship, Vernacular Architecture, Anthropology of Architecture, Documentation Methods, Intangible Heritage, Craft-skills, Video Recordings

\begin{abstract}
:
This article presents a methodology for recording and documenting building processes using an anthropological approach. The village of Esfahak, in the region of South Khorasan (Iran) is situated in an arid environment scarce in water and trees. These conditions have resulted in the development of building forms that are almost entirely made out of earth. For centuries houses have been erected by local master masons utilizing only mud bricks and without the use of any architectural drawings. This research seeks to document how building processes unfold and are implemented in the village, for both restoration and new constructions. The researcher undertakes ethnographic fieldwork examining the relationship between villagers and their architecture. This approach is based on participant observation, engaging the local community to study how buildings were and are conceived, constructed, inhabited, maintained and restored. Moreover, the research employs an apprentice-style fieldwork method to access building sites. Thus, the researcher learns by doing with masons as a way to embody local knowledge, and not merely through passive observation. The work on site, given its processual nature, is documented through audio-visual recordings from both an external and first-person perspective. The use of headmounted cameras facilitates review and discussion of building processes with the masons allowing for an in-depth understanding of this craft practice.
\end{abstract}

\section{INTRODUCTION}

\subsection{Research Premise}

Architecture features among the pan-human activities that constitute a large part of man's material culture. The study of material objects, such as buildings, has largely revolved around their cataloguing, listing, and physical documentation -an endeavour complicated mostly by practical issues, e.g. buildings state of preservation, their location, and the technologies employed to study them. Very little is considered when it comes to study the way buildings come into existence and their construction in specific socio-cultural contexts. As Ingold points out, in the study of material culture there is a tendency to overlook the creative processes that generate artefacts, as making vanishes into finished objects (Ingold, 2013, p. 7). Processes are generally neglected, even though they are necessary aspects needed for the formation and transformation of the built environment. This research is not limited to the analysis of one specific phase in the existence of a finished building, and instead examines the way architecture is made through a process, and takes into account its creation and transformation (Maudlin, Vellinga, 2014).

\subsection{Research Questions}

This article presents the initial phases of the researcher's $\mathrm{PhD}$ methodology. The main fieldwork phase is yet to be started at the moment of completion of this manuscript. The open nature of the research plan allows for the methodological discussion to be kept open for further feedback during the fieldwork. It is hoped that the methodology outlined here can be beneficial for further research. The researcher's $\mathrm{PhD}$ project investigates vernacular architecture in Central-eastern Iran taking into account its generative processes, not only cataloguing or documenting completed material objects. For this reason, the selected methodological tools must take into account aspects of vernacular architecture studies that have been generally neglected due to a focus on finished buildings. Thus, it becomes necessary to ask: how is it possible to study vernacular architectural processes? In which ways are buildings conceived and constructed, knowing that these processes are interconnected to socio-cultural and historical factors? How can we study aspects that lead to the materialization of a building, but which are themselves immaterial and cannot be crystallized into an object of study which is still in time and place?

\subsection{Research Topic and Literature Review in the Field of} Vernacular Architecture

The study takes into account earthen constructions in South Khorasan, Iran, precisely in the village of Esfahak. It is concentrated on the way people engage with local vernacular architecture in current times. The village was selected, among other reasons, because of the high level of activity and local involvement with vernacular construction in the area. These initiatives started from the local community and were not superimposed by institutions, nor by specialized professionals like architects or engineers. Moreover, this area of South Khorasan was never the focus of specialized studies on vernacular architecture (Bromberger, 1988; Oliver, 1997; Rahinmia et al., 2013).

\footnotetext{
* Corresponding author
} 
The village is constituted by two settlements: the historical site, and a new settlement that was built beside the former after the 1978 Tabas earthquake. The historical settlement laid abandoned for more than 30 years before any restoration or construction activity took place again. A group of young villagers, motivated by socio-economic reasons, decided to restart working on and in the old settlement. From 2013, architectural activities have been taken place there, attracting the attention of architects, and engineers both inside and outside Iran, and institutions like the Iranian Organization of Cultural Heritage. The researcher took part in the first international workshop on vernacular vaulting systems held in the village at the beginning of 2018. One of the most interesting aspects of this context was the way people, including professionals, villagers, craftsmen and even a foreigner like the researcher, were drawn to the village by its living architectural activities. The 'matter' was not just old ruins or material objects from the past, but the engagement of the local community with construction techniques in practice. Building activities are still taking place, and houses are not just slowly disappearing back into the surrounding soil. The old village is entirely made up of mud brick masonry structures, covered only with mud brick vaults and domes made with no centring, a typical feature of desert Central Iranian architecture (Wolff, 1966).

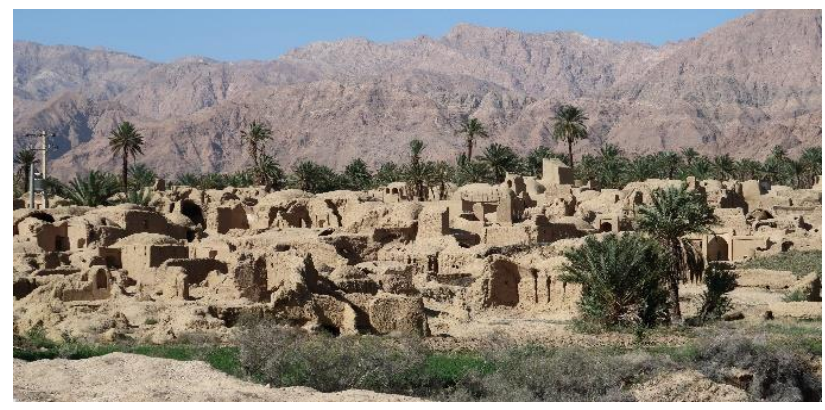

Figure 1. The village of Esfahak, South Khorasan.

From an architectural perspective it is fascinating to analyse and document these constructions, but also to study the way they are skilfully realized. Since 2003, with the UNESCO convention on intangible cultural heritage, an important shift has been made in regard to heritage studies. Inspired by noteworthy research on vernacular architecture (Correia et al., 2014; Maudlin, Vellinga, 2014; Noble, 2014), this project tries to add on to this corpus by integrating aspects of conception and making in architecture phenomena linked to practical experience that unfolds in time. The analysis is concentrated on understanding what is behind constructed objects. Studies on architecture and vernacular constructions in Iran, but also elsewhere, are mostly descriptive in nature (Rainer, 1977; Beazley, Harveston, 1982; Hejazi, Saradj, 2014). They tend to present a list of characteristics of buildings, their structural, technical and spatial features. There is not enough space here to treat the several articles and thesis which have been written on vernacular architecture in Iran in the last ten to fifteen years. It has to be pointed out though, that these studies almost exclusively deal with technological aspects of architecture. It is interesting to discover that one of the most detailed descriptions regarding traditional architectural methods of construction is found in the work of Wulff, who included a chapter on vernacular construction as part of his seminal work on crafts in Iran: 'The Traditional Crafts of Persia' (Wulff, 1966). Bromberger - an anthropologist who conducted extensive ethnographic fieldwork in Iran, focussing as well on its vernacular buildings (in the Northern provinces) - also points out that domestic architecture is generally neglected by scholarly studies (1988).
This literature review raises several new questions in regard to vernacular buildings: How do master builders work in the present as compared to the past? How do non-professionals - for example villagers or university students who come to the village to learn hands-on construction techniques - approach this craft, and what drives their interest? What are the reasons motivating old and new generations of builders to work on vernacular buildings today? What is the modus operandi of these craftsmen? How are their skills transferred, and how are new learners trying to access this form of know-how? How are problems solved on site and in what ways do these craftspeople communicate? How are these buildings conceived and 'designed' without plans and how are traditional builders dealing with academically trained architects? What is people's general interest in these material objects today? These are questions that require an 'immersion' into people's work and life. The researchers tries to get a people's perspective, knowing that material objects are inextricably interconnected to society and culture, and to a given time and place. From a single focus on buildings the researcher shifts to questioning the relationship between vernacular architecture and people's work, ideas, skills, and their cultural milieu.

\subsection{Anthropology and Ethnography of Architecture}

The research project is situated in the broader academic discussion on the anthropology of architecture and making (Ingold, 2013; Marchand, 2016, 2010, 2009, 2001), taking into account how people relate to building crafts in a specific environment. According to Ingold, anthropology is an art of inquiry, a way to perceive the events of the world in order to relate to them and correspond with them (2013, original in italic). It is not just a way to accumulate notions about the world, but a way to correlate to it. In this sense, the accumulation of notions can be compared to the mere cataloguing of buildings, which is a very useful activity, but is nonetheless incomplete.

Through anthropological research it is possible to begin working with people, not merely on them (Ingold, 2017). The researcher engages with people by carrying out participant observation, committing to understanding a culture and experiencing the world in closer contact with a specific place and people. The protracted involvement allowed by participant observation is more than simply a method, more than just interviewing research participants, as it is trying to be even physically and emotionally in relationship to another environment and society. During their master-thesis fieldwork, the researcher considered the integration of ethnographic and anthropological methods into architectural research for the first time. After a year of involvement in researching and carrying out architectural work in India, the researcher had to confront with several socio-cultural issues that became clear only after many months living in the country. Fostered by their willingness to correspond to that environment, the researcher understood how often a blind focus on material objects (buildings) gives only a shallow understanding of what it is behind artifacts. With the intention to overcome these limits, the researcher started looking at other fields of study, like anthropology and ethnography, integrating them with the fields of history and archaeology. While formulating this research project it was clear that 'being there' (on site and in a specific environment) and even working with people, is a more suitable attempt at accessing intangible aspects of architecture. This is almost uniquely allowed by carrying out fieldwork over a long period of time. With his seminal work on Yemeni masons, Marchand argues that no studies seriously consider the lives and roles of actual builders (Marchand, 2001). In his research, he is the first scholar to combine architectural training and know-how to anthropological research. 
As stated by Shefold (Oliver, 1997, p. 8): "Vernacular architecture is without architects but not without builders." Mainstream ethnographic and anthropological studies often overlook stories of individuals and their unique accretion of experience (Marchand, 2010, S3). By engaging in the craft work of masons, this research is also trying to overcome the rigid view that traditional builders are an undistinguished and unchanging group of craftsmen. How is it possible to combine anthropological and ethnographic methods in architectural research for the study of making/building processes?

\section{MAIN BODY: A METHODOLOGY FOR THE STUDY OF VERNACULAR ARCHITECTURE COMBINING AN ANTHROPOLOGICAL APPROACH}

\subsection{Methodology: A Summary}

This methodology for data collection includes the interwoven application of apprentice-style fieldwork, and the use of audiovideo recordings as one of the main source for data gathering, inclusion of research participants, and data analysis. The application of these methods is included as part of the broader participant observation approach. Participant observation is a key element of anthropological and ethnographic work, but this topic is not treated in detail in this article as it would require a longer discussion. In this excursus are only taken into account apprenticeship and video recordings as methods which are included in a larger $\mathrm{PhD}$ project frame.

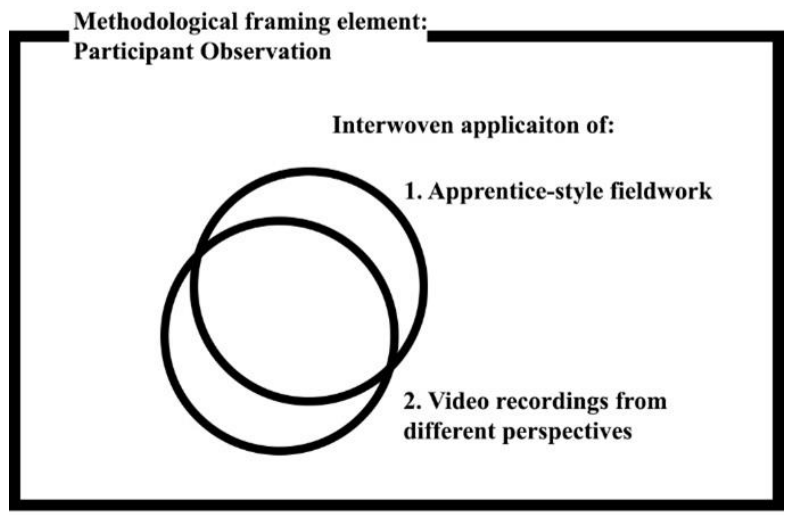

Figure 2. Scheme of the main elements part of the methodological approach.

\subsection{Theoretical background: Issues of Knowledge and Learning}

Knowledge and learning are situated in nature. Knowledge is not possessed by individuals in finite and static form, but rather derives from socio-cultural and physical interactions (Marchand, 2007 , p. 199). Learning is also a situated process, inextricably linked to any specific environment (Lave, 1988; Lave, 2011). According to Radford, knowledge is a culturally and historically encoded form of reflecting (2013). Knowledge in this sense can be considered as mere potentiality because it is not yet instantiated (ibid.- original in italic). Thus, actuation is fundamental when we talk about knowledge and learning, as what we come to know is shaped by and of the same nature of the activity through which knowledge is made into an actual form. Learning a craft is connected to practice. It is only through practice that we can learn how to do something, accessing a form of knowledge that Ryle defined as know-how (1949).
When we learn together with a more experienced person, such as a master, he or she becomes a model just by 'being there' (Lave, 2011, p. 50) - their presence is crucial for the apprentice as well as for the researcher. According to Polanyi, there is a large part of human knowledge that cannot be told, which is defined as tacit knowledge (Polanyi, 1966). As this knowledge cannot be simply explained verbally, other efforts are needed to its acquisition and eventually, dissemination. Skills and other forms of tacit knowledge need real life involvement. As stated by Sillitoe, such knowledge is gained through activities in which it is featured, practically, and its transmission is therefore dependent on its exposure to action and concrete experience (2017, p. 276). This research stresses the importance of knowing as the integration of theoretical and practical knowledge, which are always inseparable elements to be taken into account (Polanyi, 1958, p. 7). There is a clear analogy between considering different forms of knowledge as necessary and interconnected at the same time, and the importance of uniting tangible and intangible aspects of architecture. Traditional craftsmanship is listed by UNESCO among the manifestations of intangible cultural heritage as an expression of knowledge and skill, as a process of culture. UNESCO stresses the importance of safeguarding and encouraging the work of craftsmen and their knowledge transmission, particularly among local communities. The active work of craftsmen is the most important part of this work, consequently the fact that their skills and practice can be taken on by other individuals. It is important to remember that the relevance of knowledge (often tacit) in building activities goes far beyond practical building tasks performed on site, and extends to the selection of materials and all those operations which surround construction works (Sillitoe, 2017, p. 278).

\subsection{Becoming an Apprentice: Positive Aspects and Limitations}

The term apprenticeship derives from the Latin verb apprĕnděre, which means taking, receiving and retaining, thus by extension learning. The Cambridge Dictionary defines an apprentice as: "someone who has agreed to work for a skilled person for a particular period of time and often for low payment, in order to learn that person's skills." To be noticed is the stress on the terms skill and time. Apprenticeship includes several aspects (Coy, 1989; Downey et al., 2015; Marchand, 2001, 2009; Vankatesan, 2014):

1.the training of physical craft-skills and technical know-how and ability to cope with arising errors during the practice;

2.the training in managing social relationships linked to the profession, namely social knowledge;

3.the training and acquisition of specific moral principles, social values, and paradigms (world views);

4.and, implicitly in every context, the definition of a social status which is also related to gender and politics.

It would be misleading to reduce apprenticeship to just one of the aspects mentioned above. The learning process of apprentices is an immersive one, as they are totally involved in it, and they are highly physically engaged with their working environment (Marchand, 2008, p. 246). Craft-skills and technical know-how related to cultural practices can have a high degree of variation, even within the same craft. In the same way, skills learnt during apprenticeship are developed independently from other individuals, and these skills cannot be defined as a shared, invariable and uniform code (Downey et al., 2015). This indicates the uniqueness of any apprentice path. 
2.3.1 Positive Aspects: The researcher can have a first-person experience by employing this method. In this way one can start to dwell in new knowledge while going through a learning process. Marchand underlines that the apprentice method proved to be more practical in the context of builders' studies, since there was minimal use of verbal explanation in the teaching-learning processes of the builders, as learning is predominantly taking place through embodied practices (Marchand, 2001, p. 175-176). Language has several limits when it comes to describing physical actions and skills. The struggle in explaining physical action in propositional form has been a standing issue for centuries in the West. During the compilation of his Encyclopedia, Diderot found printers and typesetters inarticulate in explaining what they did, as language can hardly depict physical action (Sennet, 2008, p. 179). The issue is not a limit of the craftsmen who are unable to explain what they physically do, but in the limits of language when it comes to describing bodily actions. Practicing as an apprentice is a multidimensional experience. Practical activities foster the researcher to become bodily and sensually immersed in daily work, allowing for reflection upon their learning, mistakes and progress, as well as the difficulties and joys that accompany physical labour (Marchand, 2008, p. 249). Becoming apprentices opens up new channels of communication and expression, where practical communication often substitutes verbal one (Downey, et al., 2015). Data collected in this way are of a unique nature, requiring on site presence, working with participants, and engaging with the world. In a workshop, as well as on a building site, spoken words linked to concrete examples are more effective than any kind of written directions. In this environment, if any part of the working procedure is not understood, it is possible to immediately ask or see someone carrying out this task, resulting in a back and forth discussion (Sennet, 2008, p. 179). Human senses are also linked to skill acquisition during apprenticeship. When Grasseni, as an ethnographer and visual anthropologist, talks about 'skilled vision', she underlines the importance of acquiring a specific skill that allows her to relate to her informants. Working with cattle breeders in Northern Italy made her realize that learning to look at her host's cows was a necessary premise to access their worldview (Grasseni, 2004, p. 42).

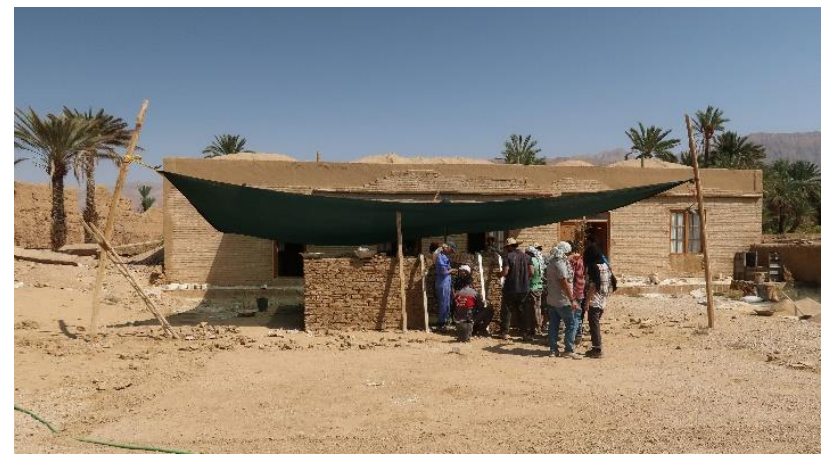

Figure 3. Hands-on workshop in Esfahak with Iranian students organized by 'Esfahak Mud Centre', September 2019.

An apprentice style fieldwork method allows for (as mentioned in the definition of apprenticeship): working next to a skilled person for a certain period of time. In the context of participant observation, apprenticeship expands the researcher's engagement in terms of time and practice. The researcher is not limited to observation, but actively takes part in the learning by employing their hands-on skills, and through having the possibility to make mistakes and potentially correct them. Merely interviewing craftsmen, in particular outside their working environment, impedes a deep understanding of a craft. Asking a craftsman about physical actions might drastically reduce the amount of data gathered. Similarly, observation of the work alone might not fully explain the subtleties of a specific craft. The importance of studying with builders lies in their knowledge that operations on site seldom go according to a specific plan. Working in a fickle and inconsistent environment, they have to provide constant solutions to problems that cannot always be anticipated (Ingold, 2013, p. 48). The physical contribution of the researcher offers privileged access to craftsmen's practices and experience, and this is achieved with an exchange of 'toil' for 'ethnographic knowledge' and craft skill (Marchand, 2008, p. 248). This active participation facilitates observation and imitation, creating a 'reciprocity of viewpoints' and a 'similar kinaesthetic experience' (Jackson in Gieser, 2008, p. 300).

Learning a craft is inseparably linked to the work environment. Considering that all learning is situated (Lave, 2011), it is only in a real setting that the researcher can experience not only the making, but also its specific cultural and physical environment. Even when dedicating most of our attention to building processes and skills, we have to remember that apprenticeship is not merely body-knowledge transfer, nor the acquisition of an implicit structure, but a form of shared cultivation of increasingly greater skilfulness towards an idealized practice and discipline of errors (Downey, Dalidowicz, Mason 2015, p. 185). Becoming an apprentice is an invaluable method to get access to specific craft-skills, learning environment, social relationships, and to explore a given socio-cultural context from a specific perspective over an extended period of time.

2.3.2 Limitations: It is not possible as researchers to become an apprentice under all contexts, as our socio-cultural background and status drastically modify the way we come to learn a craft. Notwithstanding that apprenticeship cannot be reduced to learning a skill, skill acquisition itself is embedded in the larger social milieu, where a specific value is attributed to a particular skill (Vankatesan, 2014, p. 150). This means that social knowledge related to a skill is linked to specific and localized ideas of politics, body gender, and as already stated, by economic factors and status (ibid.). The cultural dimension of knowledge transmission and learning alters and expands the experience of the practitioner, directly influencing the cognitive processes ordering our understanding of the world (Sillitoe, 2017, p. 271). Another limitation to be considered is that of time. The limited amount of time that a researcher can spend apprenticing is unlikely to guarantee a mastery of the craft, as Sillitoe points out regarding his work in New Guinea. On the other hand, the same Sillitoe admits that it is through this form of engaging during participant observation that it was possible not only to see the limits of this approach, but to get a certain degree of understanding into the tacit dimension of knowledge on the building site (2017, p. 277).

\subsection{Recording Processes with Video-cameras: Positive Aspects and Limitations}

Within social sciences, text and written forms of data collection have largely dominated all disciplines. In architecture, on the other hand, visuals that are mostly comprising technical and geometrical drawings have been the main medium employed for representation. It is argued here that it is only through the integration of multiple forms of collection methods, representation and dissemination techniques that more openended and inclusive work can be generated. Today (in particular with the launch of new technologies), greater attention to nonverbal and specifically corporeal, embodied, sensory, emotional, habitual, pre-cognitive aspects of subjectivity can further develop our understanding of the social, even in relation to architecture (Brown et al., 2008). It is believed that through filming with 
video-cameras from different perspectives - and in combination with the help of participants - it is possible to add new insights into construction processes. Nevertheless, video cannot be the only forms of data collection, analysis, and dissemination. This paragraph discusses the possible ways in which this method can be creatively employed in combination with apprenticeship as an integrative way to more common research methods. In particular, having a visual recording of a processes when examining construction - a time sequence - allows for a simultaneous examination of several audio-visual elements connected to building techniques and their acquisition. During construction there is a prevalence of non-verbal utterances that can be analyzed with the help of video recordings.

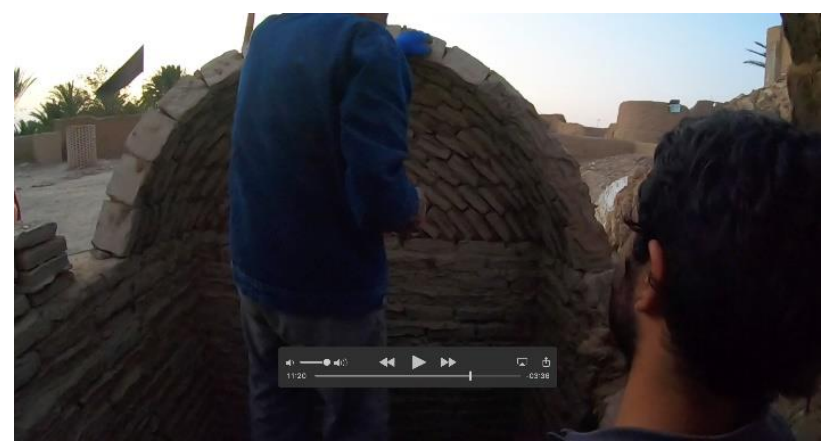

Figure 3. Excerpt of a video of a master builder in the process of constructing a barrel vault without centring, Esfahak, September 2019

2.4.1 Positive Aspects: Observation is a crucial element of learning processes, in particular for crafts. According to neurologist Marc Jannerod, the observation of someone engaged in practice acts upon our motor-based understanding of that action. He explains that vision can process images of bodily movement and activity, which then serve as inputs to the motor domains of our cognition. These images are separated into constituent postures and movements that are assigned a motor-based interpretation (Jannerod, 1994 in Marchand, 2008, p. 263-26). Similarly, video images also have a high potential for capturing processes and actions that record the patterns of life and movement (Tim Dants in Pink, 2007, p. 103). The use of video in social science, and in particular ethnography and anthropology, has been increasingly taken up by researchers (Carrol, Mesam 2018; Jarret, Liu 2018; Lahlou et al., 2015; S.Lahlou 2010, 2011; Le Bellu, 2016; Murthy, 2008; Pink et al., 2017; Pink, 2015, 2008, 2007; Shrum et al., 2007; Shrum et al., 2005; Yang, 2015). Studies range from the fields of psychology to cognitive science. Video, as compared to other visuals methods, adds the dimension of time and sound. The flow of life captured with a video-camera, especially when taking part to craft processes, may be compared to informal interviews that were not planned in advance. Video ethnography is a method which can be very inductive in nature, leaving the possibility for unexpected events to manifest. A common problem which scholars associate with everyday life and processes is the inability to access its 'flow', unless trying to slice it into a representational form crystallized and objectified for analysis (Pink et al., 2017, p. 377). These issues cannot be solved simply by utilizing videoethnography. However, the use of video recordings combined with the active participation in building activities should reveal more aspects of the work flow and construction processes. It is through the combination of apprenticeship and recordings that reflection upon construction processes can be extended beyond time spent on site. Thus, videos can be employed as a participatory tool to engage in discussion with research participants after the construction is over. The researcher shares their experience with masons on site, so the process is not only externally observed. Once the construction is over, recordings will be a bridge between the experiences of the participants and the researcher. Videos offer the possibility to be re-viewed and discussed with participants, and the flow and process of work can be partly re-experienced together. When we use video as a method, we are not simply recording what people do in order to produce visual data for analysis, rather we are taking part in a process of knowledge generation (Pink, 2007, p. 105). In the process, we also have a chance to engage with participants in a collaborative manner. Whether we are interviewing, working with someone on a building site, or reviewing videos together with research participants, another 'dimension' is added to the fieldwork. As a qualitative method, video can allow for the blurring of boundaries between visual artifacts and behaviors, becoming as significant as the words that the subject utters (Shrum et al., 2005, p. 17). The development of portable sound sync movie cameras made it possible, for the first time, to use video as an elicitation tool, therefore talking to people about their actions. showing them a video sequence of their movements (Harper, 2002, p. 14). This technique was employed for the first time in a French movie called Chronique d'un été (Chronicle of a Summer), recorded in Paris by visual anthropologist Jean Rouch and sociologist Edgar Morin in the 1950s.

Videos are recorded from different perspectives. A fixed camera on tripod records building processes as an 'external viewer'. The researcher uses a head-mounted camera to review their own work on site in collaboration and interaction with master builders. A third camera worn by the master builders records their perspective. Using a self-wearable head-mounted camera provides an insider first-person point of view that cannot be achieved otherwise. Using diverse observational perspectives allows to include research participants in further discussion, and strengthen the researcher's understanding of the dynamic interplay of construction activities. Thus, a sort of 'expanded apprenticeship' is virtually created once construction is over, by combining video replay with interviewing masons. Replay (which likely includes unexpected events) gives the researcher multiple possibilities for data triangulation. At the same time, many actions gone unnoticed during the process can be seen later, providing fresh material for more debate and analysis. Moreover, self-wearable cameras commonly available on the market are a relatively inexpensive mean to record in high quality for a researcher operating alone. They are easy to handle and can be adapted to working on site since they are resistant and designed for outdoor use. Being user friendly means that even research participants can operate them if and when needed. No cables are needed which would impede normal procedures to be carried out on a building site. Their lightweight facilitates wearing them for protracted periods of time.

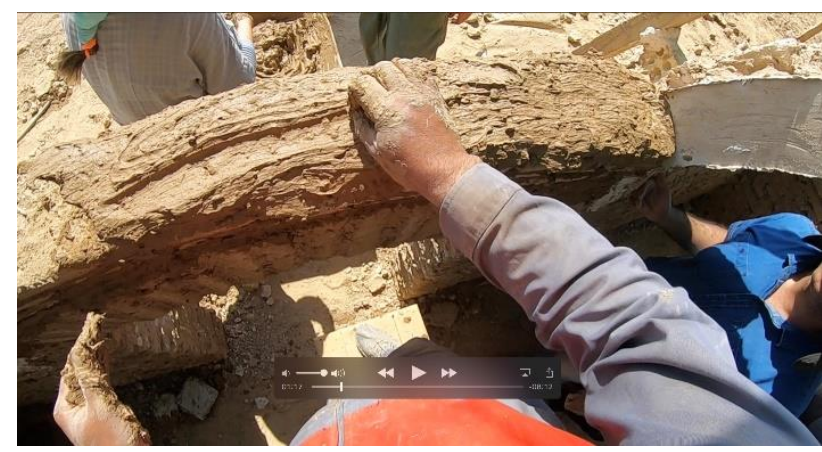

Figure 4. Excerpt of a video recorded with head-mounted camera from the builder's perspective, Esfahak, September 2019. 
2.4.2 Limitations: The work of researchers should not be only linked to technological advancements and their socially and locally bounded limits. Part of the kit of a researcher (architect-cum-anthropologist-cum-ethnographer) should be different methods, all more or less suitable to the specific circumstance in which the researcher is working. It is not always possible to record with a video camera. Video recordings will necessarily have to be focused on specific parts of the construction as it is impractical to record all phases of the building process. This is due to obvious operational limits dictated by the difficulty of constantly having cameras on site during the working day. It is also due to the amount of data recorded, as an over-collection of data (excessive recording hours) does not necessarily allow for improved analysis - on the contrary it can impede a smooth workflow. This implies that a careful selection of relevant moments of construction, important also in terms of documentation, will have to be selected and agreed upon ahead of time. For example in the case of South Khorasan and this project, it will be important to record the construction of vaults and domes without wooden centering, as this is one of the most unique features of local buildings. The use of a headmounted self-wearable camera is certainly less sophisticated than customized cameras purpose developed for each study, similar to those employed for Self-Evidence-BasedEthnography (SEBE) study by Lahlou at the LSE (Lahlou, 2010, 2011; Lahlou et al., 2015). Nevertheless, this study is not a psychologically oriented research, thus there is no need to wear a customized eye level camera. In fact, Lahlou states that the most important element of any method, including SEBE, is not the practicalities concerning devices, but building trust with the informants since methods are primarily needed to create a good environment for the research to be carried out (Lahlou, 2011, p. 624).

\section{AUDIO-VIDEO RECORDINGS
FROM DIFFERENT PERSPECTIVES}

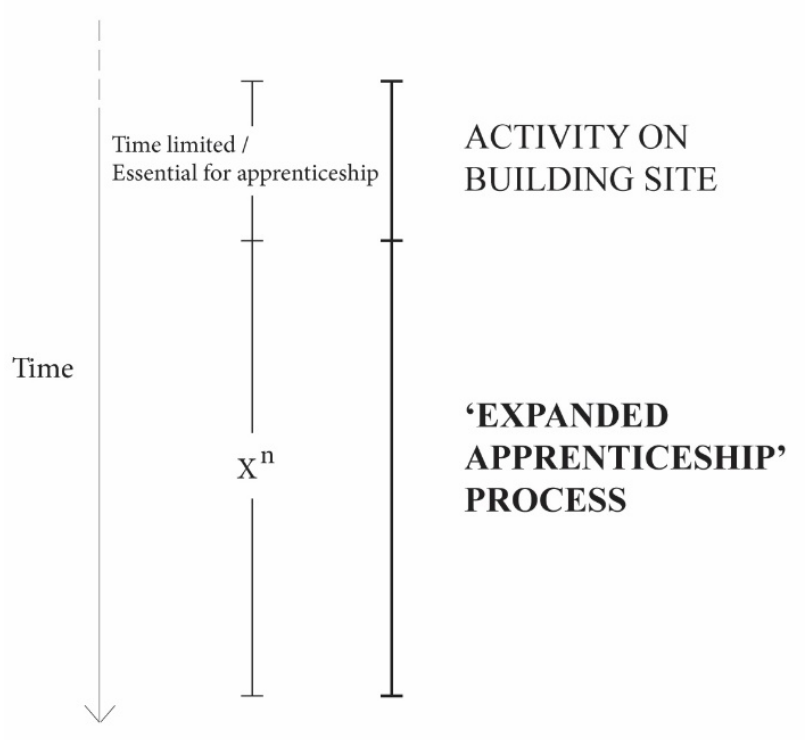

Figure 5. Scheme representing the key features of the 'Expanded Apprenticeship' process.

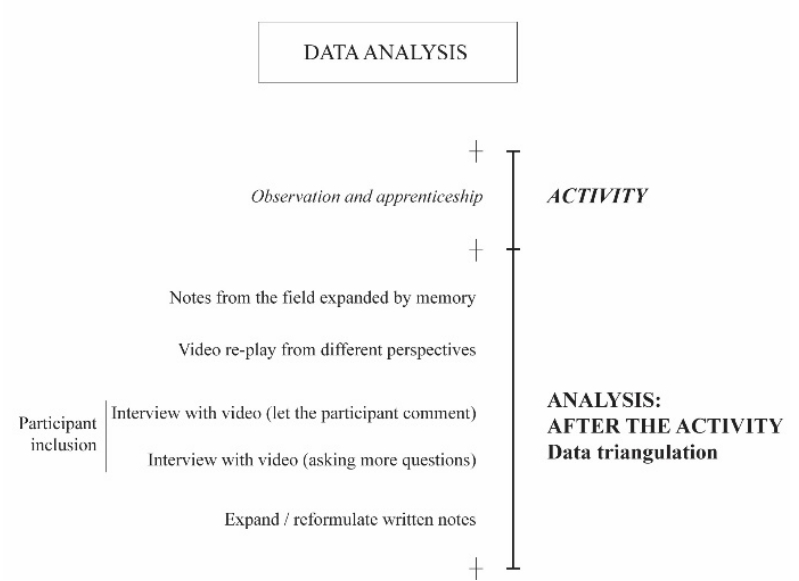

Figure 6 . Scheme of the possibilities offered by this methodology regarding data analysis and triangulation

\section{CONCLUSIONS}

The study of vernacular architecture is often limited to finished objects and what happens to them once they are embedded in social life. These finished objects are the tangible manifestations of a culture, an architecture of a place and people. In documenting the built form, it is important to also understand and study the processes behind their construction. These processes are necessary for the materialization of these buildings, and essential to understand their local meaning and their transformation through time. Processes of conception and making become manifest as building techniques, craft-skills, ways of learning and of problem solving which are intangible aspects of architecture -often unnoticed or overlooked when we only take into account the materiality of buildings. It is therefore important to inquire about the process and method whereby building making unfolds. To answer such questions, looking in particular at vernacular architecture, the proposed methodology promotes the combination of anthropology and architectural research methods. This methodology is based on spending protracted periods of time among local builders and people (participant observation), integrated with the direct engagement of the researcher in construction activities (apprenticeship). Given the importance of vision and mimicry as part of craft-skills learning, the researcher also employs video recordings to supplement their research tool kit. Recordings allow for an 'expanded apprenticeship' experience even after the work on site is over. This gives the researcher more opportunities to triangulate data and to figure out aspects of the work that might otherwise go unnoticed. Apprenticeship allows the researcher to be physically engaged with work, experiencing the process firstperson and hands-on, reinforcing data triangulation for analysis. On the other hand, implicit limitations of this approach need to be taken into consideration. It is important to note that the use of video-cameras always depends on the particular conditions created on site, social relationships, and ease of manoeuvre of the equipment. The correct occasion to employ video has to be constantly evaluated, also to avoid an over accumulation of data that are not likely to be analysed. During the development of a $\mathrm{PhD}$ thesis, it is unlikely that there will be sufficient time for undertaking a comprehensive process of learning, which generally requires several years of apprenticeship. Thus, time is amongst the most significant limitations for this type of research. Socio-cultural factors also need to be taken into account, and the researcher needs to acknowledge their own social position, which often differs drastically from that of participants. 
Culture encompasses lived activities that individuals engage in as part of their daily life as much as on a building site. Interactions and experiences in specific environments are crucial for acquiring skills and for experiencing the gradual transition from unexperienced to experienced builder (Sillitoe, 2017, p. 225). This active work, socio-culturally and historically tied, gives the researcher a closer point of view to that of the makers. In particular, in the context of vernacular architecture we often see buildings constructed without plan drawings that have been greatly altered and adapted during the construction activity. It is by trying to enter these building processes, attempting to learn specific craft-skills, and engaging in the making with builders (and their society), that an expanded perspective can be sought on vernacular buildings. The documentation and study of vernacular architecture necessitates a deeper involvement with work on-site in relationship to makers. These initial methodological thoughts are set here to test the research limits on what can be further analysed as part of vernacular architecture studies and documentation. This is made possible through a dynamic conversation with other disciplines and methods. At this stage, more questions than solutions are presented in this paper, and it will be interesting to see where this conversation might lead other researchers of vernacular architecture.

\section{ACKNOWLEDGEMENTS}

The author would like to thank the villagers and craftsmen of Esfahak for their kind welcome to the building sites in their historical settlement, allowing access to their activities. The researcher is also grateful to the team of 'Esfahak Mud Centre', professionals and volunteer students alike, for taking part in the workshops organized. The author is a recipient of the ISA Trust Travel Grant 2019 and the British Institute of Persian Studies Travel Grant April 2019, which facilitated travel to the village and allowed the researcher to ponder upon this methodology.

\section{REFERENCES}

Beazley, E., Harverson, M. 1982. Living with the Desert: Working Buildings of the Iranian Plateau. Aris \& Phillips Ltd, Warminster

Bromberger, C. 1988. Banna'i', in Encyclopaedia Iranica Online. http://www.iranicaonline.org/articles/bannai-construction (22 February 2019)

Correia, M., Di Pasquale, F., Mecca, S. (eds.) 2014. Versus: Heritage for Tomorrow, Vernacular Knowledge for Sustainable Future, FUP, Firenze

Coy, M. W. (ed.) 1989. Apprenticeship: From Theory to Method and Back Again. State University of New York Press, Albany

Downey, G., Dalidowicz, M., Mason, P. H. 2015. Apprenticeship as Method: Embodied Learning in Ethnographic practice', Qualitative Research, 15 (2), 183-200. doi: $10.1177 / 1468794114543400$

Gieser, T. 2008. Embodiment, Emotion and Empathy: A Phenomenological Approach to Apprenticeship Learning, Anthropological Theory, 8(3), 299-318. doi: $10.1177 / 1463499608093816$

Grasseni, C. 2004. Skilled vision: An apprenticeship in Breeding Aesthetics, Social Anthropology, 12 (1), 41-55. doi: $0.1017 / \mathrm{S} 0964028204000035$
Kresse, K., Marchand T.H.J. 2009. Introduction: Knowledge in Practice, Africa, 79 (1), 1-16. doi: 10.3366/E0001972008000570 Harper, D. 2002. Talking about pictures: a case for photo elicitation, Visual Studies, 17 (1), 13-26. doi: $10.1080 / 14725860220137345$

Hejazi, M., Saradj, F. M. 2014. Persian Architectural Heritage: Architecture. WIT Press, Southampton \& Boston

Ingold, T. 2013. Making: Anthropology, Archaeology, Art and Architecture. Routledge, Abingdon

Ingold, T. 2017. Anthropology Contra Ethnography, HAU: Journal of Ethnographic Theory, 1 (7), 21-26. doi: http://dx.doi.org/10.14318/hau7.1.005

Lahlou, S. 2010. Digitization and transmission of human experience, Social Science Information, 49 (3), 291-327. doi: $10.1177 / 0539018410372020$

Lahlou, S. 2011. How can we capture the subject's perspective? An evidence-based approach for the social scientist, Social Science Information, 50 (3-4), 607-65. doi: $10.1177 / 0539018411411033$

Lahlou, S., Le Bellu, S., Boesen-Mariani, S. 2015. Subjective Evidence Based Ethnography: Method and Applications, Integrative Psychological and Behavioral Science, 49, 216-238. doi: 10.1007/s12124-014-9288-9

Lave, J. 1988. Cognition in Practice. Cambridge University Press

Lave, J. 2011: Apprenticeship in Critical Ethnographic Practice. University of Chicago Press

Le Bellu, S. 2016. Learning the Secrets of the Craft Through the Real-Time Experience of Experts: Capturing and Transferring Experts' Tacit Knowledge to Novices, Perspectives interdisciplinaires sur le travail et la santé [Online], 18 (1), 133. doi : $10.4000 /$ pistes. 4685

Marchand, T.H.J. 2001. Minaret Building and Apprenticeship in Yemen. Routledge, Abingdon

Marchand, T.H.J. 2007. Crafting Knowledge: The Role of 'Parsing and Production' in the Communication of SkillBasedKnowledge Among Masons. In Harris, M. (ed.) Ways of Knowing: Anthropological Approaches to Crafting Experience and Knowledge. New York Oxford: Berghahn Books, 181-199

Marchand, T.H.J. 2008. Muscles, Morals and Mind: Craft Apprenticeship and the Formation of Person', British Journal of Educational Studies, 56 (3), 245-271. doi: 10.1111/j.14678527.2008.00407.x

Marchand, T.H.J. 2009. The Masons of Djenné. Indiana University Press, Bloomington \& Indianapolis

Marchand, T.H.J. (ed.) 2010. Making knowledge: explorations of the indissoluble relation between minds, bodies, and environment. Vol.16 Special Issue. Royal Anthropological Institute of Great Britain \& Ireland

Marchand, T.H.J. (ed.) 2016. Craftwork as Problem Solving: Ethnographic Studies of Design and Making. Ashgate Publishing, Farnham 
Maudlin, D., Vellinga, M. (eds.) 2014. Consuming Architecture: On the Occupation, Appropriation and Interpretation of Buildings. Routledge, Abingdon

Noble, A. G. 2014. Vernacular Buildings: A Global Survey, IB Tauris, London

Oliver, P. (ed.) 1997. Encyclopedia of Vernacular Architecture in the World vol. 1. Cambridge University Press

Pink, S., Sumartojo, S., Lupton, D., Labond, C. H. 2017. Empathetic technologies: digital materiality and video ethnography, Visual Studies, 32 (4), 371-381. doi: 10.1080/1472586X.2017.1396192

Pink, S. 2007. Doing Visual Ethnography: Images, Media and Representation in Research. $2^{\text {nd }}$ edn. Sage, London

Polanyi, M. 1966. The Tacit Dimension. Doubleday, New York

Rahinmia, R. et al. 2013. Bazshenakht-e Tajrobiat-e Me'mari-e Bumi dar Jonub-e Khorasan, Jahat-e Hefazat va Maremmat-e Me'mari-e Kheshti, Maskan va Mohit-e Rusta, 142, 19-32 (Persian)

Rainer, R. 1977. Anonymes Bauen im Iran. Akademische Druck, Graz

Ryle, G. 1949. The Concept of Mind. Hutchinson, London

Sennet, R. 2008. The Craftsman. Allen Lane-Penguin Books, London

Shrum, W., Duque, R., Ynalvez, M. 2007. Lessons of the Lower Ninth: Methodology and Epistemology of Video Ethnography, Technology in Society, 29, 215-225. doi: 10.1016/j.techsoc.2007.01.009

Shrum, W., Duque, R., \& Brown, T. 2005. Digital Video as Research Practice: Methodology for the Millennium, Journal of Research Practice, 1 (1), Article M4, 1-19. Available at: http://jrp.icaap.org/index.php/jrp/article/view/6/11 (19 August 2019)

Sillitoe, P. 2017. Built in Niugini: Constructions in the Highlands of Papua New Guinea. The RAI Series, Sean Kingston Publishing, Canon Pyon

Suess, E. 2014. Doors Don't Slam: Time-Based Architectural Representation, in Maudlin, D., Vellinga, M. (eds.) (2014) Consuming Architecture: On the Occupation, Appropriation and Interpretation of Buildings. Abingdon: Routledge, 243-259

Vankatesan, S. 2014. Learning to Weave; Weaving to Learn... What?, in Marchand, T.H.J. (ed.) (2010) Making knowledge: explorations of the indissoluble relation between minds, bodies, and environment. Vol.16 Special Issue. Royal Anthropological Institute of Great Britain \& Ireland, 150-166

Wulff, H. E. 1966. Traditional Crafts of Persia. MIT Press

Yang, K. 2015. Participant Reflexivity in Community-Based Participatory Research: Insights from Reflexive Interview, Dialogical Narrative Analysis, and Video Ethnography, Journal of Community \& Applied Social Psychology, 25, 447-458. doi: $10.1002 /$ casp. 2227 